\title{
Signo del macarrón
}

\section{Macaroni Sign}

\section{Marcos Raúl Álvarez ${ }^{1} \quad$ Emiliano N Mayor ${ }^{1}$}

${ }^{1}$ Hospital Interzonal General de Agudos General José de San Martín, La Plata, Buenos Aires, Argentina

Address for correspondence Marcos Raúl Álvarez, MD, Calle $53 \mathrm{~N}^{\circ}$ 390, La Plata, Buenos Aires, Argentina (e-mail: marcosralva@gmail.com).

Rev Argent Radiol 2021;85:27-30.

El signo del macarrón fue descrito por primera vez por Hiroaki Maeda en 1991. En su estudio de 23 pacientes con

diagnóstico de arteritis de Takayasu (AT), demostró el engrosamiento difuso del complejo mio-intimal con

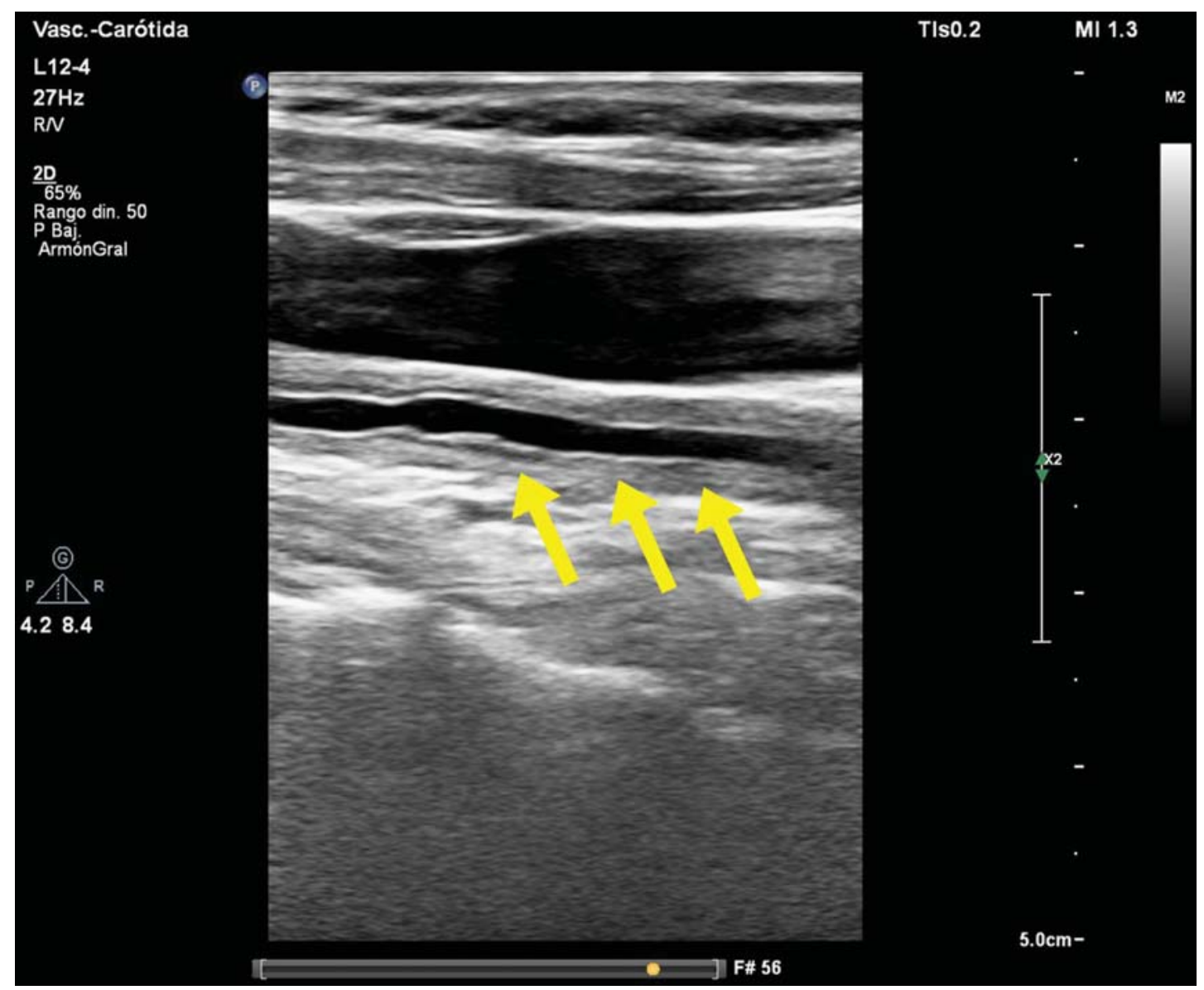

Fig. 1 Ecografía modo-B.Arteria carótida común vista en un corte longitudinal. Se visualiza engrosamiento difuso y homogéneo del complejo mio-intimal (flechas).

received

February 17, 2020

accepted

March 24, 2020

published online

August 27, 2020
DOI https://doi.org/

10.1055/s-0040-1710060.

ISSN 1852-9992.
(C) 2020. Asociación Civil Sociedad Argentina de Radiología and Federacion Argentina de Asociaciones de Radiología, Diagnóstico por Imágenes y Terapia Radiante. All rights reserved.

This is an open access article published by Thieme under the terms of the Creative Commons Attribution-NonDerivative-NonCommercial-License, permitting copying and reproduction so long as the original work is given appropriate credit. Contents may not be used for commercial purposes, or adapted, remixed, transformed or built upon. (https://creativecommons.org/ licenses/by-nc-nd/4.0/)

Thieme Revinter Publicações Ltda., Rua do Matoso 170, Rio de Janeiro, RJ, CEP 20270-135, Brazil 


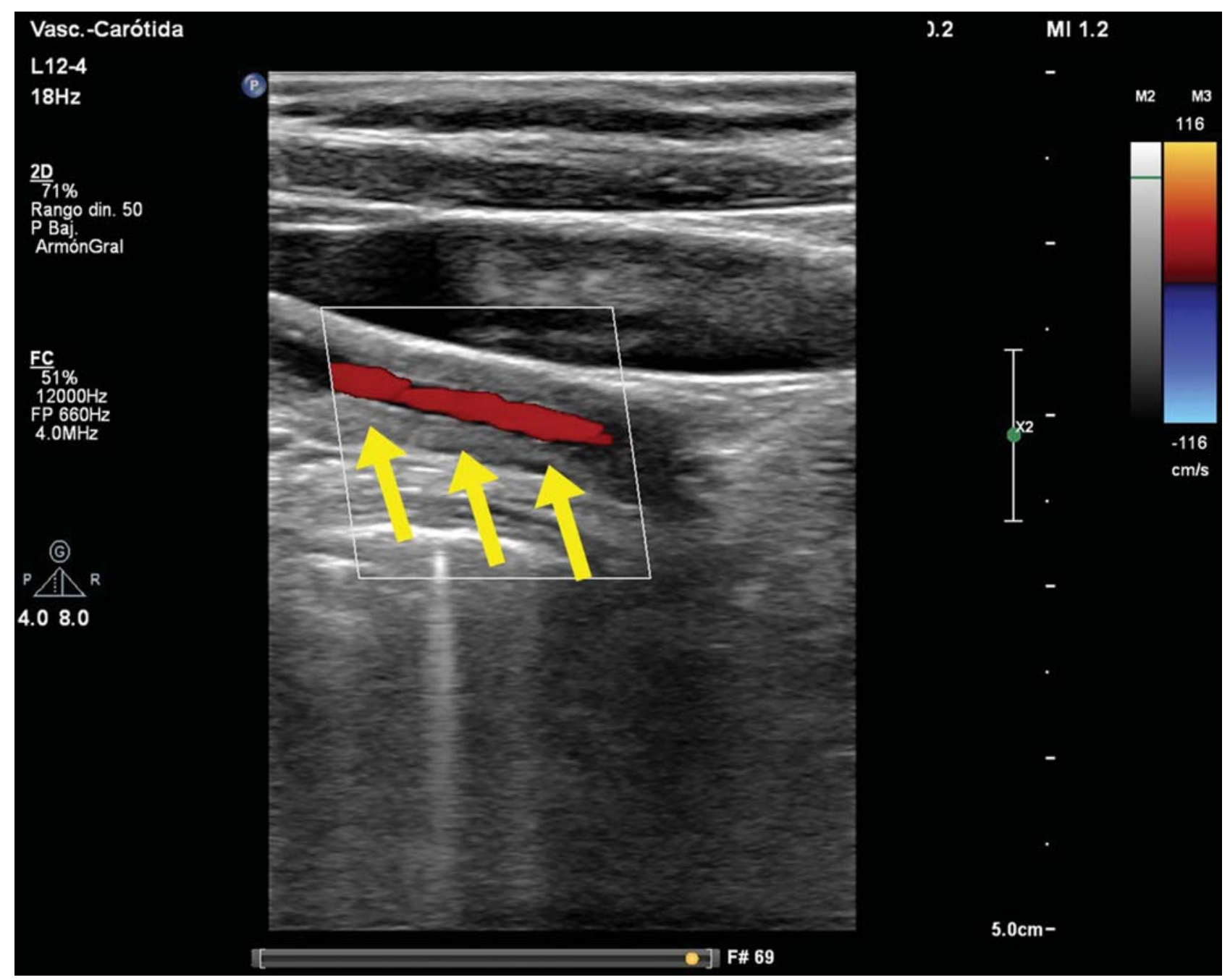

Fig. 2 Ecografía Doppler color. Se visualiza disminución de la luz arterial, con flujo anterógrado (flechas).

ecografía modo-B en 19 pacientes. ${ }^{1}$ El engrosamiento parietal homogéneo de la carótida (-Fig. 1 y - Fig. 2) se asemeja a un tipo de pasta, el macarrón, de característica forma tubular (-Fig. 3 ).

El análisis de la pared arterial mediante ecografía muestra la presencia de dos líneas ecogénicas paralelas, separadas por un espacio hipoecoico o anecoico. La línea ecogénica interna se corresponde la transición luz-íntima, siendo la línea más externa correspondiente a la interfase media-adventicia. El espacio comprendido entre ambas líneas ecogénicas se corresponde al engrosamiento combinado de la íntima y la media. El engrosamiento difuso y circunferencial de la arteria carótida permite observar el signo del macarrón, que es difícil de reconocer mediante angiografía. ${ }^{2}$

La AT es una enfermedad vascular idiopática que puede afectar la aorta toracoabdominal y sus ramas principales. Tiene mayor incidencia en mujeres y es más frecuente en el continente asiático. ${ }^{3}$

La inflamación vascular crónica conduce a un engrosamiento de la adventicia e hiperplasia intimo-medial debido al infiltrado celular. La persistencia de la reacción inflamatoria produce fibrosis de las capas media e íntima resultando en un estrechamiento de la luz arterial y ocasionalmente oclusión, trombosis o formación de aneurismas.

No hay pruebas de imágenes o de laboratorio diagnósticas consideradas gold standard para el diagnóstico de AT. La falta de sensibilidad o especificidad de los métodos, sumada a los síntomas constitucionales inespecíficos, hace que exista una demora en el diagnóstico de la enfermedad. ${ }^{4}$ Si bien la angiografía con sustracción digital ha sido tradicionalmente el método de elección para el diagnóstico de AT, la misma no permite evaluar los cambios patológicos de la pared arterial. Por otro lado, la ecografía es un método no invasivo y particularmente útil en la evaluación de la arteria carótida, reconociendo un engrosamiento

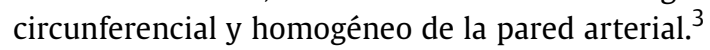

La evaluación ecográfica permite hacer un diagnóstico diferencial con otras arteritis de grandes vasos, como la de células gigantes. Esa última se caracteriza por un curso más agudo que la AT y presenta un engrosamiento mural más hipoecoico debido al edema parietal. 


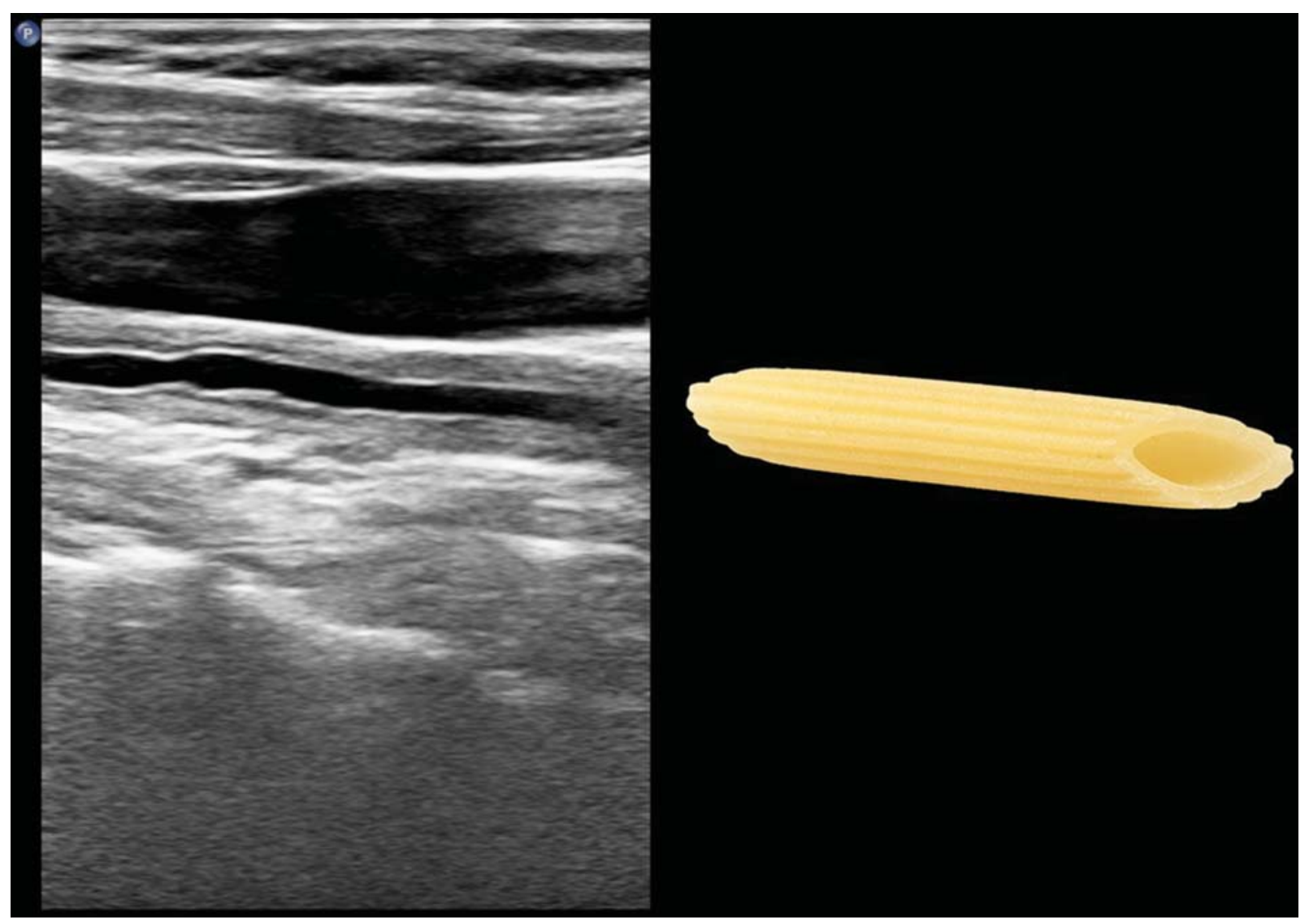

Fig. 3 Arteria carótida común vista en un corte longitudinal en modo-B y su similitud con la pasta macarrón.

\section{Conclusión}

La ecografía modo-B es un método útil para evaluar y detectar cambios patológicos en la pared de la arteria carótida. El engrosamiento difuso y concéntrico del complejo mio-intimal, conformando el signo del macarrón, es un signo específico de AT con afectación carotídea.

Protección de personas y animales

Los autores declaran que para esta investigación no se han realizado experimentos en seres humanos ni en animales.

Confidencialidad de los datos

Los autores declaran que han seguido los protocolos de su centro de trabajo sobre la publicación de datos de pacientes.
Derecho a la privacidad y consentimiento informado Los autores declaran que en este artículo no aparecen datos de pacientes.

Conflicto de Intereses

Los autores declaran no tener ningún conflicto de intereses.

\section{Bibliografía}

1 Maeda H, Handa N, Matsumoto M, Hougaku H, Ogawa S, Oku N, et al. Carotid lesions detected by B-mode ultrasonography in Takayasu's arteritis: "macaroni sign" as an indicator of the disease. Ultrasound Med Biol. 1991;17(07):695-701

2 Seike N, Ito M, Yasaka M. [Evaluation of carotid stenosis by using carotid ultrasonography]. Brain Nerve. 2010;62(12):1277-1284

3 Gotway MB, Araoz PA, Macedo TA, Stanson A, Higgins C, Ring EJ, et al. Imaging findings in Takayasu's arteritis. AJR Am J Roentgenol. 2005;184(06):1945-1950

$4 \mathrm{Kim}$ ESH, Beckman J. Takayasu arteritis: challenges in diagnosis and management. Heart. 2018;104(07):558-565 
